\title{
Prophylactic efficacy and possible mechanisms of oligosaccharides based standardized fenugreek seed extract on high-fat diet-induced insulin resistance in C57BL/6 mice
}

\author{
Amit D Kandhare ${ }^{1}$, Subhash L Bodhankar ${ }^{*}$, Vishwaraman Mohan ${ }^{2}$, Prasad A Thakurdesai ${ }^{2}$ \\ ${ }^{1}$ Department of Pharmacology, Poona College of Pharmacy, Bharati Vidyapeeth Deemed University, Erandwane, Paud Road, Pune 411038, India \\ ${ }^{2}$ Department of Scientific affairs Indus Biotech Private Limited, 1, Rahul Residency, Off Salunke Vihar Road, Kondhwa, Pune 411048, India.
}

\author{
ARTICLE INFO \\ Article history: \\ Received on: 02/12/2014 \\ Revised on: 30/12/2014 \\ Accepted on: 18/01/2015 \\ Available online: 28/03/2015 \\ Key words: \\ Fenugreek seeds; \\ Oligosaccharides; High-fat \\ diet; Insulin resistance; Glut- \\ 2; Glut-4; IRS-2; SREBP-1c.
}

\begin{abstract}
The present work was aimed to study the efficacy and possible mechanism of oligosaccharides based standardized fenugreek seed extract (SFSE-OS) on high-fat diet (HFD)-induced insulin resistance in male C57BL/6 mice. The effects of 12 weeks of oral administration of SFSE-OS (30, 60 and $100 \mathrm{mg} / \mathrm{kg}$, twice daily) were evaluated on HFD fed mice for anthropomorphic, glycemic, gene expression related and histopathological parameters. Separate groups of mice with vehicle co-administered with HFD and low-fat diet (LFD) were maintained as HFD control and LFD control respectively. Twelve weeks of SFSE-OS (60 and $100 \mathrm{mg} / \mathrm{kg}$, p.o.) administration showed significant prophylactic effects on HFD induced insulin resistance in terms of body weight, plasma glucose and insulin levels, glycated hemoglobin, insulin resistance (IR), area under the curve (AUC) of plasma glucose during oral glucose tolerance and intraperitoneal insulin tolerance. Furthermore, HFDinduced mRNA expression changes in adipose tissue, liver and skeletal muscle were prevented by SFSE-OS coadministration. Histology of sections of the pancreas showed the normal architecture in all groups of mice. SFSE-OS showed promising efficacy in prevention of HFD-induced insulin resistance through modulation of Glut-2, Glut-4, IRS-2 and SREBP-1c expression.
\end{abstract}

\section{INTRODUCTION}

Diabetes mellitus (DM) is the most common endocrine disorder of the 21 st century. The prevalence of DM is more than 194 million people worldwide (Liao et al., 2010) and estimated to increase to 333 million by 2025 (Zhu et al., 2010). Lifestyle modification measures such as diet control and exercise have been found useful in short term control of body weight and T2D management. However, long-term solution is still elusive. Existing oral anti-diabetic medications including insulin sensitizers and exogenous insulin therapy address hyperglycemia but leads to many side effects such as increased body weight, osteoporosis sodium retention, hypoglycemia and lactic acidosis (Chiang et al., 2007, Hamza et al., 2010, Stades et al., 2004). The type 2 DM (T2DM) is characterized by insulin resistance in

\footnotetext{
* Corresponding Author

Email:sbodhindus@gmail.com
}

target tissues due to both insulin action and insulin secretion with subsequent pancreatic $\beta$-cell dysfunction (Nyenwe et al., 2011). Insulin resistance (IR) is a physiological condition in which cells fail to respond to the normal actions of the hormone insulin.

The body produces insulin, but the cells in the body become resistant to insulin and are unable to use it effectively, leading to hyperglycemia. High plasma levels of insulin and glucose due to IR are a major component of the metabolic syndrome. The association between obesity and IR is well established (Hardy et al., 2012, Masuo et al., 2010).

IR is undoubtedly known as a hallmark of feature of obesity that compromises function of the pancreatic $\beta$-cell so as to cause insufficient insulin secretion and leads to T2DM (Das et al., 2013, McGarry, 2002). Strongly association between IR and microvascular (Groop et al.,2005), cardiovascular (Fontbonne, 1996) and renal (Masuo et al.,2010) complications of DM and obesity is also established. 
Therefore, safer medications with effective control on both arms (blood glucose and IR) in DM are in need (Turner etal., 1998). In recent years, many new plant derived natural products have demonstrated the potential for treatment of T2DM and its complications (Matsui et al., 2006). One such promising plant is Fenugreek (Trigonella foenum-graecum L., family: Fabaceae). Plethora of evidence confirmed beneficial effects of fenugreek seeds powder and extract on glucose and fat metabolism in animal models and patients of DM (Roberts, 2011). Fenugreek seeds reported to cause improvement in glycemic control by decreasing IR in mild T2DM patients (Gupta et al., 2001). Fenugreek seed extract in various forms demonstrated promising effects on highfat (Chaturvedi et al., 2013, Hamza et al., 2012a, Handa et al., 2005) and high sucrose (Muraki et al., 2012) diet-induced hyperlipidemia. However, the responsible component of fenugreek seed extract and its mode of action for beneficial effects on IR not been elucidated.

Among all bioactive phytoconstituents of fenugreek seeds, only component that showed efficacy towards effective restoration of both glucose and fat metabolism in DM is its fibre component (Roberts, 2011)). The endosperm of the fenugreek seed is a rich source of fiber (20\%) and gum (32.4\%) (Sharma, 1986, Sharma et al., 1990) which include water soluble (low molecular weight) and insoluble (high molecular weight) fibres. Interestingly, only water soluble low molecular weight soluble fibre fraction of fenugreek seeds demonstrated excellent efficacy in glucose and lipid management in animal and human studies (Ali et al., 1995, Evans et al., 1992). Recently, we have reported promising and dose-dependent anti-hyperglycemic effects of water-soluble low molecular weight soluble fibre fraction in diabetic mice (Kamble et al., 2013).

The soluble fibres of fenugreek seeds contain oligosaccharides along with Pinitol (methylated cyclic alcohol derivative of sugar). Oliosugers with structural similarity with a synthetic anti-diabetic oligosaccharide compound, acrabose (an $\alpha$ glucosidase inhibitor). Oligosaccharides from various natural sources have been shown anti-diabetic potential in animal studies by effective control of glucose and fat metabolism (Costa et al., 2012, Jo et al., 2014, Lee et al., 2003, Zhang et al., 2004). Furthermore, eleutheroside E (an oligosaccharide component of Eleutherococcus senticosus) was shown to ameliorates IR in animal model of type 2 diabetic db/db mice (Ahn et al., 2013). On the other hand, Pinitol obtained from other plant sources is reported to have good potential against IR for maintenance of glycemic control (Dang et al., 2010, Hernandez-Mijares et al., 2013, Kim et al., 2012, Kim et al., 2005a) through alternations in glucose (Kang et al., 2006, Kim et al., 2007) and fat metabolism (Choi et al., 2009, Geethan and Prince, 2008). The combination of naturally occurring oligosaccharide with pinitol in fenugreek seeds offers a unique option for management of insulin resistance (IR) and effective glycemic control (Watson and Preedy, 2010).

Recently, effects of oliosugers based standardized fenugreek seeds extract (SFSE-OS) containing oligosaccharide (with eleutheroside-C, methyl- $\alpha$-D-galactoside), Pinitol (methylated cyclic alcohol derivative of sugar) has been reported against experimental neuropathy models in rats (Bhaskaran and Vishwaraman, 2014). However, potential of SFSE-OS to achieve effective control of glycemia and/or IR is not been explored yet. Therefore, we undertook present study with an objective to evaluate efficacy and probable mechanism of action SFSE-OS on high-fat diet (HFD)-induced IR in C57BL/6 mice.

\section{METHODS}

\section{Animals}

Male C57BL/6 mice (age 4-weeks, 20-22 g) were used for the study. They were housed in cages at a temperature of 19.1$23.6^{\circ} \mathrm{C}$, and relative humidity 56- $66 \%$, with $12 \mathrm{~h}$ fluorescent light and $12 \mathrm{~h}$ dark cycle in an accredited animal facility (Bioneeds, Bangalore, India). The mice had free access to water ad libitum throughout the study duration except during actual measurements. All experiments were carried out between 09:00 h and 17:00 h. Institutional Animal Ethics Committee (IAEC) of Bioneed (Bangalore, India) approved the experimental protocol (BIO-IAEC-477). The experiments were performed in accordance with the guidelines on animal experimentation recommended by the Committee for Control and Supervision of Experimentation on Animals (CPCSEA), Government of India.

\section{The test compound}

The test compound, SFSE-OS supplied by Indus Biotech Private Limited (Pune, India) after preparation and characterization (HPLC and LC-MS) as per reported procedure (Bhaskaran and Vishwaraman, 2014). The sample of SFSE-OS used for the present study was standardized to Eleutheroside-C (30\%), Pinitol (48\%), Sucrose (6\%), Raffinose $(6.5 \%)$, and Stachyose $(9.5 \%)$. As SFSE-OS was water soluble, the solution was freshly prepared daily as $1 \% \mathrm{w} / \mathrm{v}$ in distilled water and orally administered twice a day to mice in volume of $10 \mathrm{mg} / \mathrm{kg}$. The doses of SFSE-OS (30, 60 and $100 \mathrm{mg} / \mathrm{kg}$, twice a day, oral) were derived from LD50 dose of $2000 \mathrm{mg} / \mathrm{kg}$ found during acute oral toxicity (AOT) study (Bodhankar et al., 2013). The vehicle or SFSE-OS were orally administered twice daily with difference of approximately $8 \mathrm{~h}$ between morning and evening administration using intragastric tube for 12 weeks.

\section{Research diets}

The Low fat diet, LFD (10 kcal \% Fat, \#D12450B, 3.85 $\mathrm{kcal} / \mathrm{g}$ ) and HFD (60 kcal \%fat, \# D12492, $5.24 \mathrm{kcal} / \mathrm{g}$ ) were purchased from Research Diet Inc., New Brunswick, NJ , USA.

\section{Development of HFD induced IR}

Mice were randomly divided into five groups of twelve mice each and administrated with treatments and diets as follows: G1 (LFD control): received vehicle $(10 \mathrm{mg} / \mathrm{kg}$ of distilled water, twice daily); G2 (HFD control): received vehicle $(10 \mathrm{mg} / \mathrm{kg}$ of distilled water, twice daily) + HFD; G3 (SFSE-OS (30): received SFSE-OS (30 mg/kg of SFSE-OS, twice daily) + HFD; G4 (SFSE- 
OS (60) : received SFSE-OS (60 mg/kg of SFSE-OS, twice daily) + HFD; G5 (SFSE-OS (100): received SFSE-OS (100 mg/kg of SFSE-OS, twice daily) + HFD. The mice were caged individually and respective diet was supplied during entire study period of 12 weeks.

Body weights of individual mouse were recorded before grouping and three times a week thereafter, during the treatment period. At end of treatment period of 12-weeks, $100 \mu \mathrm{L}$ blood were withdrawn from the retro-orbital plexus and used for glycated hemoglobin (HbAlc) levels measurement using mouse hemoglobin A1c kit (Crystal Chem, Inc., Downers Grove, IL, USA) as per manufacturer's instructions.

\section{Oral Glucose Tolerance Test (OGTT)}

On the next day of $\mathrm{HbA} 1 \mathrm{c}$ measurement, mice were fasted for $12 \mathrm{~h}$ and OGTT was performed as per reported procedure (Gallou-Kabani et al., 2007). At $0 \mathrm{~h}$ (before administration of glucose) fasting plasma glucose (FPG) was measured using Accu-Chek Performa Blood Glucose Meter (Roche Diagnostics India Private Ltd, Mumbai, India) and glucose load $(2 \mathrm{~g} / \mathrm{kg})$ was administered orally. Blood was withdrawn at 30, 60,120 , and $180 \mathrm{~min}$, plasma was obtained after centrifugation and PG measurements were done. Additional blood was collected at 0 and $120 \mathrm{~min}$, plasma was separated and used for insulin measurement with mouse insulin ELISA kit (ALPCO Diagnostics, Salem, NH, USA).

From the values of FPG and fasting insulin, the HOMAIR was calculated as per reported formula (Matsuda and DeFronzo, 1999). The graph of PG levels versus time (min) was plotted and area under the OGTT curve (AUC-OGTT) was calculated with the help of Prism v6.0 (GraphPad Software Inc, La Jolla, CA, USA).

\section{Intraperitoneal Insulin Tolerance Test (IPITT)}

Three days after OGTT, 6 mice per group were selected for IPITT. Mice were fasted for $4 \mathrm{~h}$ and FPG was measured using Accu-Chek Performa Blood Glucose Meter (Roche Diagnostics India Private Ltd). After $30 \mathrm{~min}$, mice were administered intraperitoneally with insulin $\left(0.5 \mathrm{IU} / \mathrm{kg}\right.$, Actrapid ${ }^{\circledR}$, Novo Nordisk India Pvt Ltd, Bangalore, India). PG was measured at 30, 60, and $120 \mathrm{~min}$ from insulin administration. The graph of PG levels versus time (min) was plotted and area under the IPITT curve (AUC-IPITT) was calculated with the help of Prism v6.0 (GraphPad Software Inc, La Jolla, CA, USA).

\section{Gross Necropsy}

At end of the experimental period, all mice were sacrificed using $\mathrm{CO}_{2}$ asphyxiation and subjected to gross necropsy. Four samples of adipose tissues, liver, pancreas and skeletal muscle from each group were preserved in liquid nitrogen for gene expression analysis by reverse transcriptase-polymerase chain reaction (RT-PCR). Two samples of pancreas from each group were preserved in $10 \%$ neutral buffered formalin for histopathology.

\section{Gene expression analysis by RT-PCR}

Four tissue samples of adipose tissue, liver, pancreas and skeletal muscle from each group was used for RT-PCR analysis using kits (Biotools B \& M Labs, Spain) according to manufacturer's instructions. Total RNA was extracted from each tissue. The PCR mixture was amplified in a DNA thermal cycler (Eppendorf India Ltd, Chennai, India) by using gene specific primers (Table 1). PCR products were run on $1 \%$ agarose gels, stained with ethidium bromide. The expression of all the genes was assessed by generating densitometry data for band intensities in different sets of experiments and was generated by analyzing the gel images on the Image J program (Version 1.33, Wayne Rasband, National Institutes of Health Bethesda, MD, USA). The band intensities were compared with constitutively expressed $\beta$ actin which served as a control for sample loading and integrity. The intensity of mRNAs was standardized against that of the $\beta$ actin mRNA from each sample, and the results were expressed in a quantitative manner as PCR-product/ $\beta$-actin mRNA ratio.

\section{Histopathology}

The samples from pancreas were embedded in paraffin wax, sectioned at $4 \mu \mathrm{m}$ and stained with haematoxylin and eosin (H\&E) and observed under compound microscope using a Zeiss intravital microscopy setup (Zeiss Axioscope A1, Carl Zeiss MicroImaging, Jena, Germany) with a 40X magnification for histological examinations.

\section{Statistical analysis}

All statistical analysis was performed using GraphPad Prism 6.0 (GraphPad Software, Inc, La Jolla, CA, USA). Data of body weight and biochemical measurements was analyzed by separate One-way ANOVA followed by Dunnett's test separately for each parameter. A value of $\mathrm{P}<0.05$ was considered to be statistically significant.

\section{RESULTS}

\section{Effect on body weight and Glycemic parameters}

The data of effects of treatments on body weight and glycemic parameters (fasting glucose level, OGTT and IPITT, plasma insulin, HOMA-IR and HbAlc levels) are presented in Table 2. At the end of study (12-weeks), significant gain in the body weight $(\mathrm{P}<0.05)$ and HbAlc $(\mathrm{P}<0.001)$ was observed in HFD control mice as compared to LFD control mice (Table 2). The mean body weights in LFD fed mice was $20.66 \mathrm{~g}$ whereas that of HFD control mice were was $33.40 \mathrm{~g}$ (gain of increase $4.74 \mathrm{~g}$., $17.7 \%)$

The body weights of HFD mice co-administered with SFSE-OS (60) group showed significant $(\mathrm{P}<0.01)$ reduction by $3.73 \mathrm{~g}(15.17 \%)$ as compared to HFD control group. At the end of 12-week of study period, HFD control group showed significant ( $\mathrm{P}<0.001$ ) increase in mean $\mathrm{HbAlc}$ values of $5.43 \%$ as compared to HBA1c values of LFD control mice (2.94\%). Mean HbA1c levels of HFD mice co-administered with SFSE-OS (30, 60 and 
$100 \mathrm{mg} / \mathrm{kg}$, p.o.) were $4.11 \%, 2.96 \%$ and $3.13 \%$ respectively. These values were significantly $(\mathrm{P}<0.001)$ less as compared to HFD control mice (5.43\%).

\section{Effect of SFSE-OS during OGTT}

At the end of study (12-weeks), during OGTT, the LFD fed mice showed values of FPG $(114.44 \mathrm{mg} / \mathrm{dl})$, fasting plasma insulin $(0.36 \mu \mathrm{g} / \mathrm{L}), 2 \mathrm{~h}$ post-glucose plasma insulin $(0.52 \mu \mathrm{g} / \mathrm{L})$, IR (0.11) and AUC-OGTT (31998.30) (Table 2). In the same period, HFD control mice showed significantly $(\mathrm{P}<0.001)$ higher values of FPG (175.44 mg/dl, 53.30\% increase), fasting plasma insulin $(1.12,211.11 \%$ increase $)$, IR $(0.51,363.63 \%$ increase $)$, AUC-OGTT (42966.70, 34.28\% increase) respectively. However, the values of $2 \mathrm{~h}$ post-glucose plasma insulin $(0.73 \mu \mathrm{g} / \mathrm{L})$ was not significantly different as compared with corresponding value of LFD control mice during OGTT.

At the end of study (12-weeks), during OGTT, HFD fed mice co-administrated with SFSE-OS (30, 60 and $100 \mathrm{mg} / \mathrm{kg}$, p.o.) showed significantly $(\mathrm{P}<0.001)$ less values of FPG levels of $129.33,119.83$ and $125.67 \mathrm{mg} / \mathrm{dl}$ respectively. These values were $26.28 \%, 31.69 \%$ and $28.36 \%$ less as compared with plasma glucose values of HFD control mice.

Fasting insulin levels of SFSE-OS (60 and $100 \mathrm{mg} / \mathrm{kg}$, p.o.) co-administrated HFD mice showed significantly less values of 0.70 and $0.57 \mu \mathrm{g} / \mathrm{L}(37.5 \%$ and $49.10 \%$ less) as compared to that of HFD control mice. However, fasting plasma insulin levels of SFSE-OS $(30 \mathrm{mg} / \mathrm{kg}$ ) co-administered mice show values of 0.89 , (20.53\% less) which was not significant as compared HFD control mice. The values of $2 \mathrm{~h}$ post-glucose plasma insulin was not significantly different in any of SFSE-OS co-administrated group as compared to HFD control mice.

During OGTT, the mean value of IR of SFSE-OS (60 and $100 \mathrm{mg} / \mathrm{kg}$, p.o.) co-administrated mice was $0.23(54.90 \%$ less) and 0.19 (62.74\% less) and were significantly lower ( $\mathrm{P}<$ 0.05 and 0.01 respectively) as compared to mean values of IR of HFD control mice (0.51). However, IR of SFSE-OS $(30 \mathrm{mg} / \mathrm{kg}$ ) co-administrated mice $(0.33,35.29 \%$ less $)$ showed no significant difference as compared HFD control mice (0.51).

The values of AUC-OGTT in SFSE-OS (60 and 100 $\mathrm{mg} / \mathrm{kg}$ ) co-administrated mice were 33290 and 36336.30 respectively. These values were significantly $(\mathrm{P}<0.001$ and $\mathrm{P}<$ 0.01 ) less by $22.52 \%$ and $15.43 \%$ as compared to that of HFD control group. However, SFSE-OS $(30 \mathrm{mg} / \mathrm{kg}$ ) co-administrated mice showed reduction of $6.74 \%$ in AUC-OGTT which was not significant as compared with that of HFD control group (42967).

\section{Effect of SFSE-OS during IPITT}

The effects of treatments on AUC-IPITT are presented in Table 2. On insulin (0.5 U/kg, i.p.) load, AUC-IPITT of control mice was 17227.50 , which was significant $(\mathrm{P}<0.001)$ rise $(103.0$ $\%$ ) in AUC-IPITT over corresponding value of LFD control group (8482.50). SFSE-OS (30, 60 and $100 \mathrm{mg} / \mathrm{kg}$, p.o.) coadministrated mice showed AUC-IPITT values of 11350.00, 9822.50 and 12795.00 respectively which are $34.12 \%, 42.98 \%$ and $25.73 \%$ less as compared to corresponding values observed in HFD control mice (17227.50).

\section{Effect on mRNA expressions in adipose tissues}

The effects of SFSE-OS on mRNA expressions of Glut2, Glut-4, IRS-2 and SREBP-1c in adipose tissue are presented as Fig.1. There was significant down-regulation in the mRNA expressions of Glut-2, Glut-4 and IRS-2 in adipose tissues of HFD control mice $(\mathrm{P}<0.01, \mathrm{P}<0.05$ and $\mathrm{P}<0.001$ respectively) as compared with LFD control mice. Treatment with SFSE-OS (100 $\mathrm{mg} / \mathrm{kg}$, p.o.) significantly up-regulated the mRNA expression of Glut-2 $(\mathrm{P}<0.01)$ in adipose tissue as compared to HFD control mice. The mRNA expression of Glut-4 in adipose tissue was significantly up-regulated ( $\mathrm{P}<0.01$ and $\mathrm{P}<0.01$, resp.) in SFSEOS (60 and $100 \mathrm{mg} / \mathrm{kg}$, p.o.) treated mice as compared to HFD control mice. As compared with HFD control mice, the mRNA expression of IRS-2 in adipose tissue was significantly upregulated $(\mathrm{P}<0.01)$ by SFSE-OS $(100 \mathrm{mg} / \mathrm{kg}$, p.o. $)$ treatment.

On the other hand, SFSE-OS (30 mg/kg, p.o.) failed to produce any significant up-regulation in mRNA expression of Glut-2, Glut-4 and IRS-2 in adipose tissue when compared with HFD control mice (Fig. 1A, 1B, 1C and 1D). The level of SREBP1c mRNA expression in adipose tissue of HFD control mice was significantly up-regulated $(\mathrm{P}<0.001)$ as compared to LFD control mice. Up-regulation in SREBP-1c mRNA expression was significantly reduced $(\mathrm{P}<0.001)$ by the SFSE-OS $(100 \mathrm{mg} / \mathrm{kg}$, p.o.) treatment when compared with HFD control mice. But when compared with HFD control mice, the SREBP-1c mRNA expression in adipose tissue of SFSE-OS $(30 \mathrm{mg} / \mathrm{kg}$, p.o.) treated mice was not significantly down-regulated (Fig. 1E).

\section{Effect of SFSE-OS on mRNA expressions in liver}

The effects of SFSE-OS on gene expressions of Glut-2, Glut-4, IRS-2 and SREBP-1c in liver are presented as Fig. 2. The mRNA expression of Glut-2 and IRS-2 in liver was significantly down-regulated $(P<0.001)$ in HFD control mice as compared to LFD control mice. This down-regulated mRNA expression of Glut-2 and IRS-2 in liver was significantly up-regulated $(P<$ $0.001)$ by the SFSE-OS $(100 \mathrm{mg} / \mathrm{kg}$, p.o.) treatment as compared to HFD control mice. However, treatment with SFSE-OS (30 and $60 \mathrm{mg} / \mathrm{kg}$, p.o.) did not produce any significant up-regulation in the mRNA expression level of Glut-2 and IRS-2 in liver as compared to HFD control mice. Moreover, the Glut-4 mRNA expression was non-significantly down-regulated in HFD control mice as compared to LFD control mice and SFSE-OS (30, 60 and $100 \mathrm{mg} / \mathrm{kg}$, p.o.) treated mice also did not show any significant change in Glut-4 mRNA expression as compared to HFD control mice (Fig. 2A, 2B, 2C and 2D). The liver SREBP-1c mRNA expression of HFD control mice was significantly up-regulated $(P$ $<0.001)$ as compared to LFD control mice. When compared with HFD control mice, the liver SREBP-1c mRNA expression was significantly and dose dependently down-regulated $(P<0.01, P<$ 0.001 and $P<0.001$, resp.) by SFSE-OS $(30,60$ and $100 \mathrm{mg} / \mathrm{kg}$, p.o.) treatment (Fig. 2A and 2E). 
A

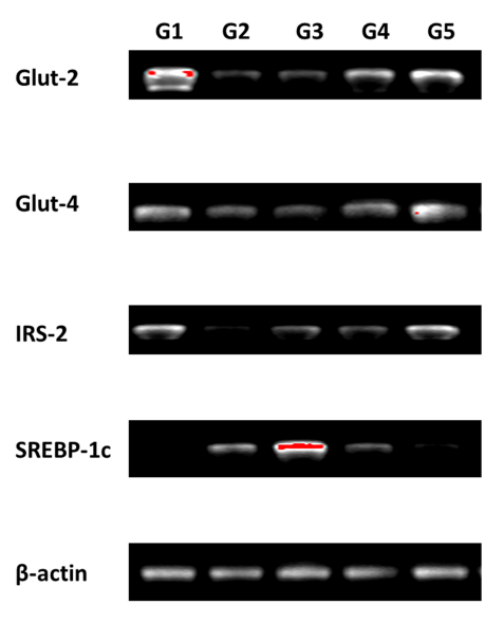

B

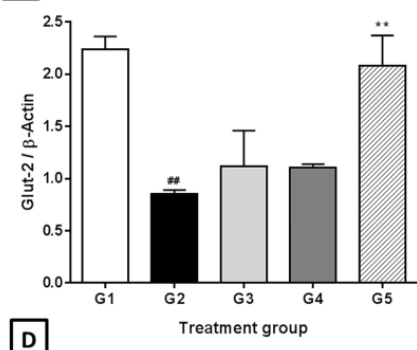

168 bp

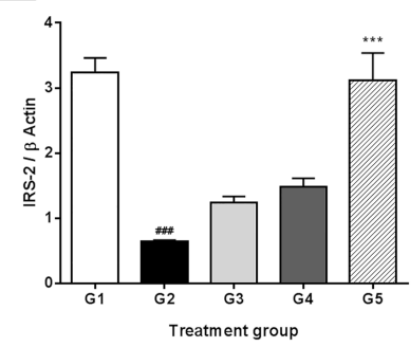

C
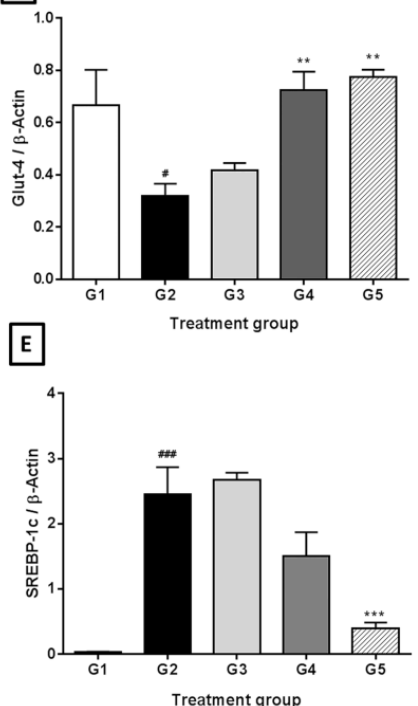

Fig. 1: Effect of SFSE-OS on HFD induced alteration in adipose tissue. Qualitative (A) and quantitative representation mRNA expression of Glut-2 (B), Glut-4 (C), IRS-2 (D) and SREBP-1c (E). Data are expressed as mean \pm S.E.M. $(n=4)$ and analyzed by one-way ANOVA followed by Dunnett's test for each parameter separately. G1 - LFD control; G2 - HFD control; G3 - SFSE-OS (30) + HFD; G4 - SFSE-OS (60) + HFD; G5 - SFSE-OS (100) +HFD **P < 0.01, ***P < 0.001 as compared to HFD control and \#\#P $<0.01$, \#\#\#P $<0.001$ as compared to LFD control..

A

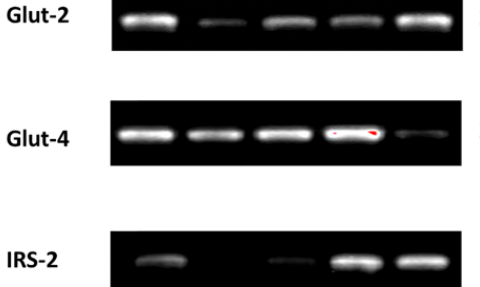

SREBP-1c

$\beta$-actin

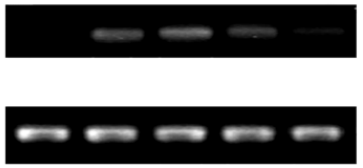

B

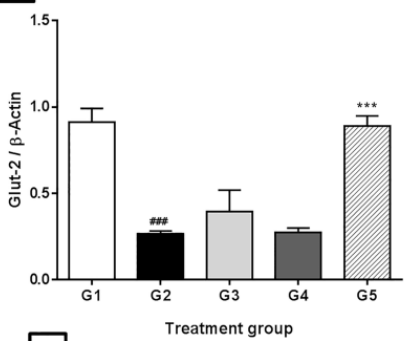

$168 \mathrm{bp}$

$229 \mathrm{bp}$

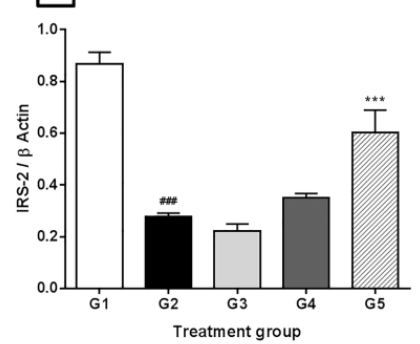

C

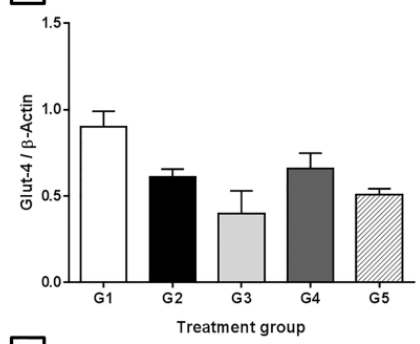

E

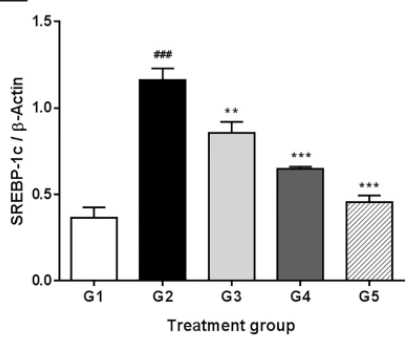

Fig. 2: Effect of SFSE-OS on HFD induced alterations in mRNA expression (reverse transcriptase PCR method) of Liver. Qualitative (A) and quantitative representation mRNA expression of Glut-2 (B), Glut-4 (C), IRS-2 (D) and SREBP-1c (E). Data are expressed as mean \pm S.E.M. (n=4) and analyzed by one-way ANOVA followed by Dunnett's test for each parameter separately. G1 - LFD control; G2 - HFD control; G3 - SFSE-OS (30) + HFD; G4 - SFSE-OS (60) + HFD; G5 - SFSE-OS $(100)+$ HFD. $* * P<0.01$, ***P $<0.001$ as compared to HFD control and \#\#\#P $<0.001$ as compared to LFD control.

Table 1: Gene specific Primer sequences for Glut-2, Glut-4, IRS-2, IL-6, SREBP-1c and $\beta$-actin used for RT-PCR analysis.

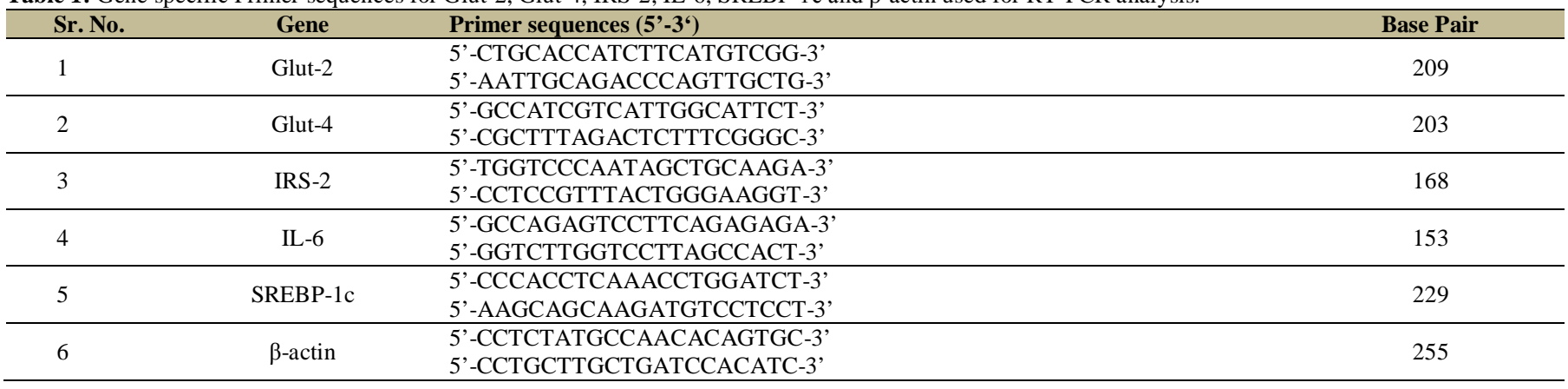




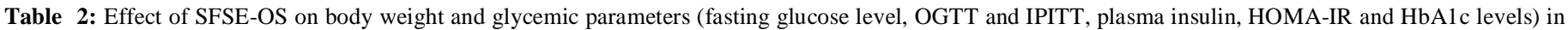
mice.

\begin{tabular}{|c|c|c|c|c|c|}
\hline \multirow{2}{*}{ Parameters } & G1 & G2 & G3 & G4 & G5 \\
\hline & LFD control & HFD control & SFSE-OS (30) + HFD & SFSE-OS (60) + HFD & SFSE-OS $(100)+$ HFD \\
\hline Body weight (g) & $28.66 \pm 0.78$ & $33.40 \pm 0.65^{\#}$ & $29.67 \pm 1.10^{\mathrm{ns} 1}$ & $28.33 \pm 1.01 * *$ & $29.62 \pm 0.80^{\mathrm{ns} 1}$ \\
\hline HbA1c (\%) & $2.94 \pm 0.23$ & $5.43 \pm 0.22 \# \# \#$ & $4.11 \pm 0.22 * * *$ & $2.96 \pm 0.09 * * *$ & $3.13 \pm 0.12 * * *$ \\
\hline \multicolumn{6}{|l|}{ OGTT } \\
\hline FPG (mg/dL) & $114.44 \pm 5.53$ & $175.44 \pm 3.73 \# \# \#$ & $129.33 \pm 2.01 * * *$ & $119.83 \pm 1.38 * * *$ & $125.67 \pm 2.73 * * *$ \\
\hline $\begin{array}{l}\text { Fasting Plasma } \\
\text { insulin }(\mu \mathrm{g} / \mathrm{L})\end{array}$ & $00.36 \pm 0.12$ & $01.12 \pm 0.13 \# \# \#$ & $00.89 \pm 0.13^{\mathrm{ns} 1}$ & $00.70 \pm 0.11^{*}$ & $00.57 \pm 0.07 * *$ \\
\hline $\begin{array}{l}2 \mathrm{~h} \text { post-glucose } \\
\text { plasma insulin }(\mu \mathrm{g} / \mathrm{L})\end{array}$ & $00.52 \pm 0.08$ & $00.73 \pm 0.09 \mathrm{~ns}$ & $00.70 \pm 0.11^{\mathrm{ns} 1}$ & $00.73 \pm 0.11^{\mathrm{ns} 1}$ & $00.89 \pm 0.10^{\mathrm{ns} 1}$ \\
\hline HOMA-IR & $00.11 \pm 0.04$ & $00.51 \pm 0.06 \# \# \#$ & $00.33 \pm 0.05^{\mathrm{ns} 1}$ & $00.23 \pm 0.04 *$ & $00.19 \pm 0.03 * *$ \\
\hline AUC-OGTT & $31998.30 \pm 1777.04$ & $42966.70 \pm 861.36 \# \# \#$ & $40068.80 \pm 1885.73^{\mathrm{ns} 1}$ & $33290.00 \pm 834.66^{* * *}$ & $36336.30 \pm 944.46^{* *}$ \\
\hline AUC-IPITT & $8482.50 \pm 191.01$ & $17227.50 \pm 1132.05 \# \# \#$ & $11350.00 \pm 192.04 * * *$ & $9822.50 \pm 291.80 * * *$ & $12795.00 \pm 673.00 * * *$ \\
\hline
\end{tabular}

Data are expressed as mean \pm S.E.M. and analyzed by one-way ANOVA followed by Dunnett's test for each parameter separately. ns - not significant, \#\#\#P < 0.001 as compared to LFD control and ns1 - not significant, $* \mathrm{P}<0.05$, **P $<0.01$, ***P $<0.001$ as compared to HFD control.

\section{A}

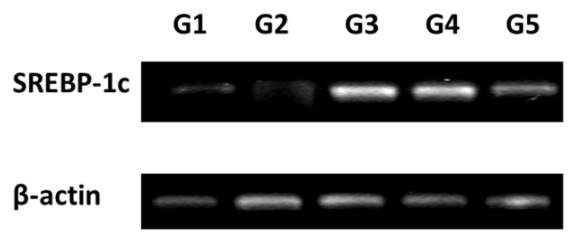

229 bp
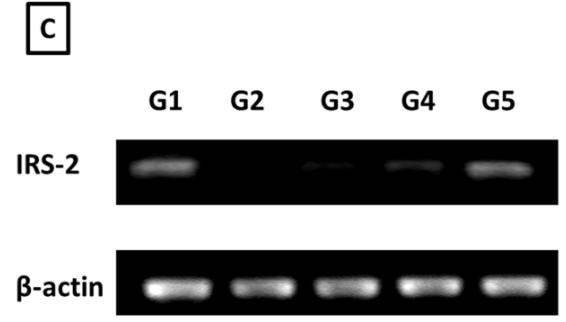

B

$255 \mathrm{bp}$

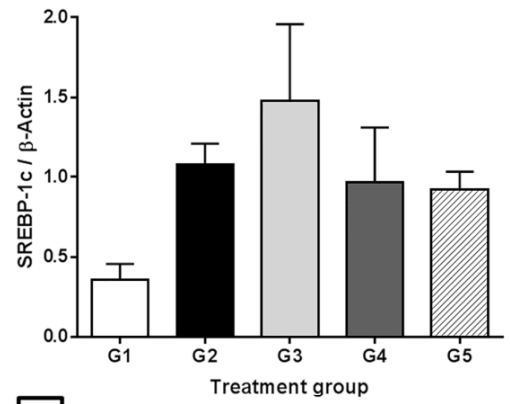

D

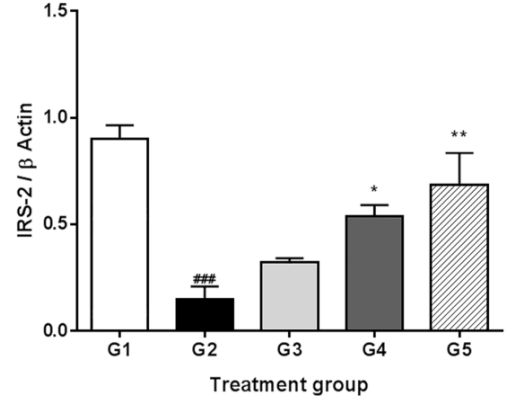

Fig. 3: Effect of SFSE-OS on HFD induced alteration in mRNA expression (reverse transcriptase PCR method) of pancreas (A, B) and skeletal muscle (C and D). Data are expressed as mean \pm S.E.M. $(n=4)$ and analyzed by one-way ANOVA followed by Dennett's test for each parameter separately. G1 - LFD control; G2 - HFD control; G3 - SFSE-OS (30) + HFD; G4 - SFSE-OS (60) + HFD; G5 - SFSE-OS (100) + HFD. *P $<0.05$, **P $<0.01$, ***P $<0.001$ as compared to HFD control and \#\#\#P $<0.001$ as compared to LFD control.
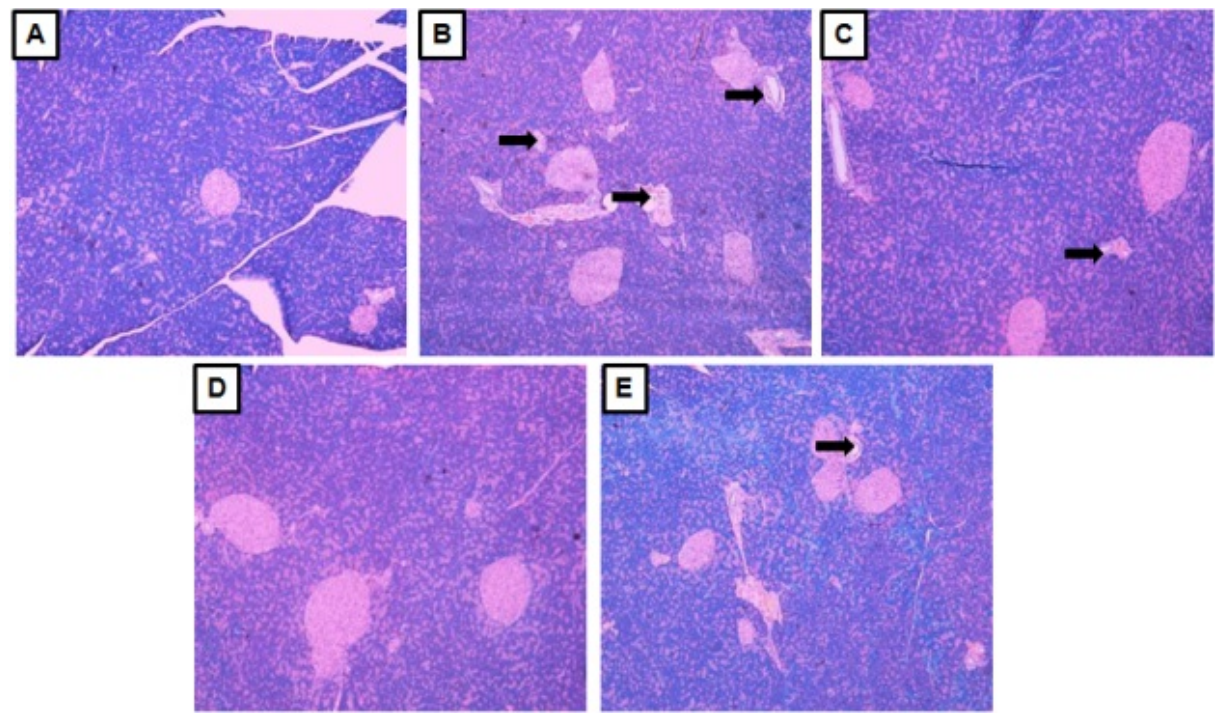

Fig. 4: Photomicrographs of sections of representative sample of pancreas of mice from LFD control (A); HFD control; (B), SFSE-OS (30 mg/kg) treated (C); SFSE-OS (60 mg/kg) treated (D) and SFSE-OS (100 mg/kg) treated (E). H\&E staining at 40X. Arrow indicates necrosis in pancreatic beta cell of Langerhans. 


\section{Effect of SFSE-OS on mRNA expression in skeletal muscle}

The effects of SFSE-OS on gene expression of IRS-2 in skeletal muscle are presented as Fig. 3. There was significant down-regulation $(P<0.001)$ in skeletal muscle IRS-2 mRNA expression in HFD control mice as compared to LFD control mice. Treatment with SFSE-OS (60 and $100 \mathrm{mg} / \mathrm{kg}$, p.o.) significantly and dose dependently up-regulated $(P<0.001)$ the mRNA expression of IRS-2 in skeletal muscle as compared to HFD control mice. However, SFSE-OS (30 mg/kg, p.o.) treated mice failed to produce any significant up-regulation in IRS-2 mRNA expression in skeletal muscle when compared with HFD control mice (Fig. 3A and 3B).

\section{Effect of SFSE-OS on m-RNA expressions in pancreas}

The effects of SFSE-OS on gene expression of SREBP1c in pancreas are presented as Fig. 3. The pancreatic SREBP-1c mRNA expression of HFD control mice did not differ significantly as compared to LFD control mice and SFSE-OS (30, 60 and 100 $\mathrm{mg} / \mathrm{kg}$, p.o.) treatment also did not produce any significant change in the pancreatic SREBP-1c mRNA expression as compared to HFD control mice (Fig. 3C and 3D).

\section{Effect on histopathological alteration in mice pancreas}

The effects of treatments on histopathological alternations found during histology of pancreatic tissues are presented as Fig. 4. The sections of pancreas from LFD control, HFD control mice and SFSE-OS (30, 60 and $100 \mathrm{mg} / \mathrm{kg}$, p.o.) treated mice showed no histopathological alterations in pancreatic tissue and showed normal size and shape of acini and islet of Langerhans.

\section{DISCUSSION}

In the etiology of IR, diet played a important role. Features like weight and fat mass gain, polydipsia and hyperglycemia are hallmark of progressive worsening of IR.

Several reports of postprandial blood glucose reduction and improved insulin sensitivity by fenugreek seed extracts in nondiabetic (Fairchild et al., 1996, Jenkins et al., 1980, O'Connor et al., 1981) and diabetic (Gupta et al., 2001, Losso et al., 2009, Mohan and Balasubramanyam, 2001, Roberts, 2011) subjects exist. The combination of naturally occurring oligosaccharide with pinitol from fenugreek seeds unique and offers excellent potential for management of IR. Therefore, the present study was aimed at evaluation of efficacy and mechanism of SFSE-OS, a unique composition with oligosaccharide and pinitol, in well-validated animal model of diet induced IR (HFD in C57/BL6 mice). Recent advance in preclinical pharmacology allow us to mimic human obese condition in laboratory animals with ease of weight gain as well as IR. HFD feeding for 12 weeks is known to mimic modern fat rich dietary conditions (Surwit et al., 1988). HFD induced IR model is well validated and known to have excellent predictive validity (Buettner et al., 2007, Pagliassotti et al., 1994). This model exhibits an array of features of IR including hyperglycemia and hyperinsulinemia (Ahren and Pacini, 2002). In the present study, 12-weeks of HFD feeding resulted in increase in body weight, and FPG and insulin levels in HFD control mice as compared to LFD control mice. Our observations of weight gain, hyperglycemia, and hyperinsulinemia in mice confirmed induction of IR and in line with earlier reports (Azman et al., 2012, Veerapur et al., 2012, Zhang et al., 2010).

Treatment with SFSE-OS showed significant antihyperglycemic effects with prevention of weight gain despite of HFD feeding. Prevention of body weight gain shown by SFSEOS can be attributed to balance between fat burning catabolic (reduction of weight) effect and anabolic (increased muscle mass) effect. In our study during OGTT, HFD control mice showed elevated plasma insulin levels, which represent important characteristics of IR. The elevated insulin levels during the OGTT represents reduced glucose elimination and impaired insulin utilization (Fonseca, 2003). Furthermore, HFD control mice exhibited higher AUC than LFD control mice similar to earlier reports (Abdin et al., 2010, Zhang et al., 2010). In the present study, SFSE-OS co-administration with HFD prevented hyperglycemia during OGTT and IPITT and better utilization of exogenous insulin during IPITT. Administration of SFSE-OS showed time-dependent suppression of increased blood glucose and insulin levels as shown by reduced AUC-OGTT and AUCIPITT. The results of present study are also consistent with the earlier reports of beneficial effects of chronic administration of fenugreek seeds significantly decreased plasma insulin, AUC of OGTT and HOMA-IR (Hamza et al., 2012b).

These observation can be attributed oligosaccharide content of SFSE-OS similar to reports of slowing glucose intestinal glucose absorption either by carbohydrate hydrolyzing enzyme inhibition (Jo et al., 2014) or induction of intestinal gluconeogenesis (Mithieux and Gautier-Stein, 2014). Another probable mechanism behind observed effects during present study can be increased utilization of insulin-regulated glucose into peripheral tissues. This notion is supported by past reports of activation of an insulin-signaling pathway by fenugreek seed extract in general (Vijayakumar et al., 2005) . The reports of insulinotropic activity of oligosaccharides (Kim et al., 2009, Kim et al., 2005b, Lee et al., 2003) and pinitol (Bates et al., 2000, Dang et al., 2010, Kim et al., 2012) suggested their major role in reduction of blood glucose and IR observed in the present study.

To explore molecular mechanism of action in further details we have analyzed mRNA expression important targets in organs related to IR namely skeletal muscle, liver and white adipose tissue (WAT) (Fischer-Posovszky et al., 2007, Korenblat et al., 2008). Skeletal muscle is primary site for IR because insulin-stimulated glucose uptake takes place in skeletal muscle (DeFronzo and Tripathy, 2009). Impairment of insulin signaling transduction pathways leads to IR (Leturque et al., 2009, Previs et al., 2000). Insulin receptor substrate-2 (IRS-2) is known to regulate insulin signaling in liver. In liver, IRS-2 play central role in hepatic nutrient homeostasis via anabolic effects of insulin through the activation of phosphatidylinositol 3-kinase/Akt) 
pathway cascade (Andersson et al., 2004, Hirashima et al., 2003), inhibit gluconeogenesis, apoptosis (Valverde et al., 2003, Valverde et al., 2004) and GLUT-2 translocation to the plasma membrane, resulting in hepatic IR (Pessin and Saltiel, 2000). Fasted state increases and feeding (and weight increase) reduces expression of IRS-2 (Kubota et al., 2000). In the present study, adipose tissue, liver and skeletal muscles of HFD control mice showed reduced levels of IRS-2 expression whereas pancreatic IRS-2 expression was unaltered. The findings from histology of pancreas are also in line with mRNA expression findings. SFSEOS co-administration with HFD prevented decrease in the expression of IRS-2 in target organs (adipose tissue, liver and skeletal muscles) and expectedly prevented weight gain and fasting insulin elevation (hyperinsulinemia) in the present study. IRS2 and downstream PI-3K/Akt-->Foxo1 signaling cascade play key roles in many functions of insulin/Insulin like growth factor -1 (IGF-1) that plays important role in control of DM and its complications (Guo, 2013). In the present study, SFSE-OS coadministration with HFD, down regulated the mRNA expression of two important integral isoforms of glucose transporter proteins namely of Glut-2 and Glut-4 in liver and adipose tissues. Glut-2 plays critical role in glucose transport and metabolism to regulate body glucose homeostasis whereas Glut-4 is a key gene that mainly responsible for insulin-stimulated glucose transport in tissues (Charron et al., 1999). Insulin-dependent translocation of Glut-2 resulted in regulation of glucose homeostasis via activation of insulin PI3K/phosphorylated protein kinase B (p-Akt) pathway (Watson et al., 2004). HFD fed mice are known to decrease Glut-2 mRNA expression in liver and adipose tissue to cause hyperglycemia (Azman et al., 2012, Yang et al., 2012). Glut-4 is mainly expressed in liver as well as adipocytes. Clinical evidence of decreased Glut-4 expression in obese and DM patients confirmed its role in glucose homeostasis (Berger et al., 1989, Cushman and Wardzala, 1980, Sivitz et al., 1989). Glut-4 increases insulin sensitivity through glucose uptake via a pathway where insulin binds to its cell surface receptors to facilitate glucose transport in tissue (Kwon et al., 2007) whereas increased expression of Glut-4 in adipose tissue improves glucose disposal and insulin sensitivity in vivo (Shepherd et al., 1993, Yang et al., 2012). Moreover, up-regulation in the Glut-4 gene expression in transgenic $\mathrm{db} / \mathrm{db}$ mice was found to be correlated with amelioration of insulin resistance (Brozinick et al., 2001). Therefore, SFSE-OS is suggested to increase insulin sensitivity and glucose uptake in skeletal muscles through Glut 2 upregulation. The molecular mechanism of insulin resistance in diabetes involves impaired Glut-4 gene expression via sterol regulatory element binding proteins 1c (SREBP-1c) pathway (Horton et al., 2002, Kang et al., 2010). SREBP-1c gene is one of the responsible factors for development of IR in many organs (Letexier et al., 2003). Up-regulated SREBP-1c expression in HFD control mice in the liver and adipose tissues are in line with earlier reports of up-regulation in SREBP-1c mRNA in HFDinduced insulin resistance mice and subsequent induction of insulin resistance (Horton et al., 2002, Shimomura et al., 2000).
Over-expression of SREBPs, the membrane-bound transcription factors, are implicated in biosynthesis of fatty acids and triglycerides (Foufelle and Ferré, 2002, Osborne, 2000). SREBP1c play vital role in insulin signaling by inhibiting IRS-2 expression in the liver and adipose tissue (Takahashi et al., 2005) and modulation of glucose-stimulated Glut-2 gene expression (Andersson et al., 2004). In the present study, SFSE-OS administration caused down-regulation in expression of SREBP-1c in liver and adipose tissue that may enhance expression of Glut-2 as well as Glut-4 to facilitate insulin-stimulated glucose transporter in target organ to improve insulin sensitivity. Our study results are in support with earlier reports on mechanism of fenugreek seeds against IR (Vijayakumar et al., 2010, Vijayakumar et al., 2005) and suggested SFSE-OS is a responsible component for action against IR. In the past, dietary oligosaccharides were reported to improve insulin sensitivity in obese horses (Respondek et al., 2011). In addition, dietary pinitol is reported to have antihyperglycemic effects be mediated via the insulin signaling pathway (Do et al., 2008) and reported as an insulin sensitizer or insulin mediator in 3T3-L1 preadipocytes in vitro (Do et al., 2008). Therefore, oligosaccharides and pinitol can be envisaged as responsible for efficacy of SFSE-OS against hyperglycemia and IR in the present study. The stimulation of glucose uptake by SFSEOS against HFD induced IR can be contributed by possible prevention of fat mass accumulation by SFSE-OS. In the past, oligosaccharide (Smith et al., 2010, Wang et al., 2011) and pinitol (Choi et al., 2009, Geethan and Prince, 2008) from other sources demonstrated beneficial effects on lipid and cholesterol metabolism. However, more investigations directed towards effects of SFSE-OS on obesity-induced IR are required to confirm such possibilities.

\section{CONCLUSIONS}

SFSE-OS administration showed promising prophylactic efficacy against HFD-induced IR development suggested good potential for management of obese and prediabetes population. This effect, at least in part, mediated through the improved insulin sensitivity and improvement in glucose transport to target organs. The up-regulation of IRS2, Glut 2 and Glut 4 and downregulation of SREBP-1c in liver and adipose tissues, perhaps plays crucial role in the mechanism of action of SFSE-OS.

\section{ACKNOWLEDGEMENTS}

The authors would like to acknowledge Dr. S. S. Kadam, Vice-Chancellor and Dr. K. R. Mahadik, Principal, Poona College of Pharmacy, Bharati Vidyapeeth Deemed University, Pune, India for providing infrastructure and Indus Biotech Private Limited, Pune, India for research support.

\section{REFERENCES}

Abdin AA, Baalash AA, Hamooda HE. Effects of rosiglitazone and aspirin on experimental model of induced type 2 diabetes in rats: focus on insulin resistance and inflammatory markers. J Diabetes Complications. 2010;24:168-78. 
Ahn J, Um MY, Lee H, Jung CH, Heo SH, Ha TY. Eleutheroside E, An Active Component of Eleutherococcus senticosus, Ameliorates Insulin Resistance in Type 2 Diabetic $\mathrm{db} / \mathrm{db}$ Mice. Evid Based Complement Alternat Med. 2013;2013:934183.

Ahren B, Pacini G. Insufficient islet compensation to insulin resistance vs. reduced glucose effectiveness in glucose-intolerant mice. American journal of physiology Endocrinology and metabolism. 2002; 283:E738-E44.

Ali L, Azad Khan AK, Hassan Z, Mosihuzzaman M, Nahar $\mathrm{N}$, Nasreen T, et al. Characterization of the hypoglycemic effects of Trigonella foenum graecum seed. Planta Med. 1995;61:358-60.

Andersson U, Filipsson K, Abbott CR, Woods A, Smith K, Bloom SR, et al. AMP-activated protein kinase plays a role in the control of food intake. J Biol Chem. 2004;279:12005-8.

Azman KF, Amom Z, Azlan A, Esa NM, Ali RM, Shah ZM, et al. Antiobesity effect of Tamarindus indica L. pulp aqueous extract in high-fat diet-induced obese rats. Journal of Natural Medicines. 2012;66: 333-42.

Bates SH, Jones RB, Bailey CJ. Insulin-like effect of pinitol. British journal of pharmacology. 2000;130:1944-8.

Berger J, Biswas C, Vicario PP, Strout HV, Saperstein R, Pilch PF. Decreased expression of the insulin-responsive glucose transporter in diabetes and fasting. Nature. 1989;340:70-2.

Bhaskaran S, Vishwaraman M. A composition for treating neuropathy, a process and a method of treatment thereof. WIPO: WO2014162276 A1: Indus Biotech Private Limited, Pune, India; 2014.

Bodhankar SL, Kandhare A, Mohan V, Thakudesai PA. Toxicological evaluations of the low molecular weight galactomannans from fenugreek seeds [OP-9]. XXXIII Annual Conference Of Society Of Toxicology (STOX), India For Synergy Of Toxicology Research In SAARC Countries Mathura, India2013.

Brozinick JT, McCoid SC, Reynolds TH, Nardone NA, Hargrove DM, Stevenson RW, et al. GLUT4 overexpression in $\mathrm{db} / \mathrm{db}$ mice dose-dependently ameliorates diabetes but is not a lifelong cure. Diabetes. 2001;50:593-600.

Buettner R, Schölmerich J, Bollheimer LC. High-fat Diets: Modeling the Metabolic Disorders of Human Obesity in Rodents. Obesity. 2007; 15:798-808.

Charron MJ, Katz EB, Olson AL. GLUT4 gene regulation and manipulation. J Biol Chem. 1999;274:3253-6.

Chaturvedi U, Shrivastava A, Bhadauria S, Saxena JK, Bhatia G. A mechanism-based pharmacological evaluation of efficacy of Trigonella foenum graecum (fenugreek) seeds in regulation of dyslipidemia and oxidative stress in hyperlipidemic rats. J Cardiovasc Pharmacol. 2013;61:505-12.

Chiang C-K, Ho T-I, Peng Y-S, Hsu S-P, Pai M-F, Yang S$\mathrm{Y}$, et al. Rosiglitazone in Diabetes Control in Hemodialysis Patients With and Without Viral Hepatitis Infection Effectiveness and side effects. Diabetes Care. 2007;30:3-7.

Choi MS, Lee MK, Jung UJ, Kim HJ, Do GM, Park YB, et al. Metabolic response of soy pinitol on lipid-lowering, antioxidant and hepatoprotective action in hamsters fed-high fat and high cholesterol diet. Mol Nutr Food Res. 2009;53:751-9.

Costa GT, Guimarães SB, Sampaio HAdC. Fructooligosaccharide effects on blood glucose: an overview. Acta Cirurgica Brasileira. 2012;27:279-82.

Cushman S, Wardzala L. Potential mechanism of insulin action on glucose transport in the isolated rat adipose cell. Apparent translocation of intracellular transport systems to the plasma membrane. J Biol Chem. 1980;255:4758-62.

Dang NT, Mukai R, Yoshida K, Ashida H. D-pinitol and myo-inositol stimulate translocation of glucose transporter 4 in skeletal muscle of C57BL/6 mice. Biosci Biotechnol Biochem. 2010;74:1062-7.
Das P, Bhattacharjee D, Bandyopadhyay SK, Bhattacharya G, Singh R. Association of obesity and leptin with insulin resistance in type 2 diabetes mellitus in Indian population. Indian $\mathrm{J}$ Physiol Pharmacol. 2013;57:45-50.

DeFronzo RA, Tripathy D. Skeletal muscle insulin resistance is the primary defect in type 2 diabetes. Diabetes Care. 2009;32:S157-S63.

Do GM, Choi MS, Kim HJ, Woo MN, Lee MK, Jeon SM. Soy pinitol acts partly as an insulin sensitizer or insulin mediator in 3T3-L1 preadipocytes. Genes \& nutrition. 2008;2:359-64.

Evans AJ, Hood RL, Oakenfull DG, Sidhu GS. Relationship between structure and function of dietary fibre: a comparative study of the effects of three galactomannans on cholesterol metabolism in the rat. Br J Nutr. 1992;68:217-29.

Fairchild RM, Ellis PR, Byrne AJ, Luzio SD, Mir MA. A new breakfast cereal containing guar gum reduces postprandial plasma glucose and insulin concentrations in normal-weight human subjects. Br J Nutr. 1996;76:63-73.

Fischer-Posovszky P, Wabitsch M, Hochberg Z. Endocrinology of adipose tissue-an update. Horm Metab Res. 2007;39:314-21.

Fonseca V. Clinical significance of targeting postprandial and fasting hyperglycemia in managing type 2 diabetes mellitus. Current Medical Research and Opinion®. 2003;19:635-1.

Fontbonne A. Insulin-resistance syndrome and cardiovascular complications of non-insulin-dependent diabetes mellitus. Diabetes Metab. 1996;22:305-13.

Foufelle F, Ferré P. New perspectives in the regulation of hepatic glycolytic and lipogenic genes by insulin and glucose: a role for the transcription factor sterol regulatory element binding protein1c. Biochem J. 2002;366:377-91.

Gallou-Kabani C, Vige A, Gross MS, Rabes JP, Boileau C, Larue-Achagiotis $\mathrm{C}$, et al. $\mathrm{C} 57 \mathrm{BL} / 6 \mathrm{~J}$ and $\mathrm{A} / \mathrm{J}$ mice fed a high-fat diet delineate components of metabolic syndrome. Obesity. 2007;15:19962005.

Geethan PK, Prince PS. Antihyperlipidemic effect of Dpinitol on streptozotocin-induced diabetic Wistar rats. J Biochem Mol Toxicol. 2008;22:220-4.

Groop PH, Forsblom C, Thomas MC. Mechanisms of disease: Pathway-selective insulin resistance and microvascular complications of diabetes. Nat Clin Pract Endocrinol Metab. 2005;1:100-10.

Guo S. Molecular Basis of Insulin Resistance: The Role of IRS and Foxo1 in the Control of Diabetes Mellitus and Its Complications. Drug discovery today Disease mechanisms. 2013;10:e27-e33.

Gupta A, Gupta R, Lal B. Effect of Trigonella foenumgraecum (fenugreek) seeds on glycaemic control and insulin resistance in type 2 diabetes mellitus: a double blind placebo controlled study. J Assoc Physicians India. 2001;49:1057-61.

Hamza N, Berke B, Cheze C, Agli A-N, Robinson P, Gin H, et al. Prevention of type 2 diabetes induced by high fat diet in the C57BL/6J mouse by two medicinal plants used in traditional treatment of diabetes in the east of Algeria. J Ethnopharmacol. 2010;128:513-8.

Hamza N, Berke B, Cheze C, Le Garrec R, Umar A, Agli A$\mathrm{N}$, et al. Preventive and curative effect of Trigonella foenum-graecum L. seeds in C57BL/6J models of type 2 diabetes induced by high-fat diet. J Ethnopharmacol. 2012a;142:516-22.

Hamza N, Berke B, Cheze C, Le Garrec R, Umar A, Agli A$\mathrm{N}$, et al. Preventive and curative effect of $<\mathrm{i}>$ Trigonella foenumgraecum $</ \mathrm{i}>\mathrm{L}$. seeds in C57BL/6J models of type 2 diabetes induced by high-fat diet. J Ethnopharmacol. 2012b;142:516-22.

Handa T, Yamaguchi K, Sono Y, Yazawa K. Effects of fenugreek seed extract in obese mice fed a high-fat diet. Biosci Biotechnol Biochem. 2005;69:1186-8. 
Hardy OT, Czech MP, Corvera S. What causes the insulin resistance underlying obesity? Curr Opin Endocrinol Diabetes Obes. 2012;19:81-7.

Hernandez-Mijares A, Banuls C, Peris JE, Monzo N, Jover A, Bellod L, et al. A single acute dose of pinitol from a naturallyoccurring food ingredient decreases hyperglycaemia and circulating insulin levels in healthy subjects. Food Chem. 2013;141:1267-72.

Hirashima Y, Tsuruzoe K, Kodama S, Igata M, Toyonaga T, Ueki $\mathrm{K}$, et al. Insulin down-regulates insulin receptor substrate-2 expression through the phosphatidylinositol 3-kinase/Akt pathway. J Endocrinol. 2003;179:253-66.

Horton JD, Goldstein JL, Brown MS. SREBPs: activators of the complete program of cholesterol and fatty acid synthesis in the liver. J Clin Invest. 2002;109:1125-31.

Jenkins DJ, Wolever TM, Taylor RH, Reynolds D, Nineham R, Hockaday TD. Diabetic glucose control, lipids, and trace elements on long-term guar. Br Med J. 1980;280:1353-4.

Jo S-H, Ha K-S, Lee J-W, Kim Y-C, Apostolidis E, Kwon Y-I. The reduction effect of low molecular weight chitosan oligosaccharide (GO2KA1) on postprandial blood glucose levels in healthy individuals. Food Science and Biotechnology. 2014;23:971-3.

Kamble H, Kandhare AD, Bodhankar S, Mohan V, Thakurdesai P. Effect of low molecular weight galactomannans from fenugreek seeds on animal models of diabetes mellitus. Biomedicine \& Aging Pathology. 2013;3:145-51.

Kang JH, Tsuyoshi G, Han IS, Kawada T, Kim YM, Yu R. Dietary Capsaicin Reduces Obesity-induced Insulin Resistance and Hepatic Steatosis in Obese Mice Fed a High-fat Diet. Obesity. 2010;18:780-7.

Kang MJ, Kim JI, Yoon SY, Kim JC, Cha IJ. Pinitol from soybeans reduces postprandial blood glucose in patients with type 2 diabetes mellitus. J Med Food. 2006;9:182-6.

Kim HJ, Park KS, Lee SK, Min KW, Han KA, Kim YK, et al. Effects of pinitol on glycemic control, insulin resistance and adipocytokine levels in patients with type 2 diabetes mellitus. Ann Nutr Metab. 2012;60:1-5.

Kim JI, Kim JC, Kang MJ, Lee MS, Kim JJ, Cha IJ. Effects of pinitol isolated from soybeans on glycaemic control and cardiovascular risk factors in Korean patients with type II diabetes mellitus: a randomized controlled study. Eur J Clin Nutr. 2005a;59:456-8.

Kim JN, Chang IY, Kim HI, Yoon SP. Long-term effects of chitosan oligosaccharide in streptozotocin-induced diabetic rats. Islets. 2009;1:111-6.

Kim MJ, Yoo KH, Kim JH, Seo YT, Ha BW, Kho JH, et al. Effect of pinitol on glucose metabolism and adipocytokines in uncontrolled type 2 diabetes. Diabetes Res Clin Pract. 2007;77 Suppl $1:$ S247-51.

Kim YW, Kim KH, Choi HJ, Lee DS. Anti-diabetic activity of beta-glucans and their enzymatically hydrolyzed oligosaccharides from Agaricus blazei. Biotechnol Lett. 2005b;27:483-7.

Korenblat KM, Fabbrini E, Mohammed BS, Klein S. Liver, muscle, and adipose tissue insulin action is directly related to intrahepatic triglyceride content in obese subjects. Gastroenterology. 2008;134:1369-75.

Kubota N, Tobe K, Terauchi Y, Eto K, Yamauchi T, Suzuki $\mathrm{R}$, et al. Disruption of insulin receptor substrate 2 causes type 2 diabetes because of liver insulin resistance and lack of compensatory beta-cell hyperplasia. Diabetes. 2000;49:1880-9.

Kwon O, Eck P, Chen S, Corpe CP, Lee J-H, Kruhlak M, et al. Inhibition of the intestinal glucose transporter GLUT2 by flavonoids. The FASEB Journal. 2007;21:366-77.

Lee HW, Park YS, Choi JW, Yi SY, Shin WS. Antidiabetic effects of chitosan oligosaccharides in neonatal streptozotocin-induced noninsulin-dependent diabetes mellitus in rats. Biol Pharm Bull. 2003;26:1100-3.

Letexier D, Pinteur C, Large V, Fréring V, Beylot M. Comparison of the expression and activity of the lipogenic pathway in human and rat adipose tissue. J Lipid Res. 2003;44:2127-34.

Leturque A, Brot-Laroche E, Le Gall M. GLUT2 mutations, translocation, and receptor function in diet sugar managing. American journal of physiology Endocrinology and metabolism. 2009;296: E985-E92.

Liao Z, Chen X, Wu M. Antidiabetic effect of flavones from Cirsium japonicum DC in diabetic rats. Arch Pharm Res. 2010;33:353-62.

Losso JN, Holliday DL, Finley JW, Martin RJ, Rood JC, Yu Y, et al. Fenugreek bread: a treatment for diabetes mellitus. J Med Food. 2009;12:1046-9.

Masuo K, Rakugi H, Ogihara T, Esler MD, Lambert GW. Cardiovascular and renal complications of type 2 diabetes in obesity: role of sympathetic nerve activity and insulin resistance. Curr Diabetes Rev. 2010;6:58-67.

Matsuda M, DeFronzo RA. Insulin sensitivity indices obtained from oral glucose tolerance testing: comparison with the euglycemic insulin clamp. Diabetes Care. 1999;22:1462-70.

Matsui T, Ogunwande I, Abesundara K, Matsumoto K. Anti-hyperglycemic potential of natural products. Mini Reviews in Medicinal Chemistry. 2006;6:349-56.

McGarry JD. Banting lecture 2001: dysregulation of fatty acid metabolism in the etiology of type 2 diabetes. Diabetes. 2002;51:7-18.

Mithieux G, Gautier-Stein A. Intestinal glucose metabolism revisited. Diabetes Res Clin Pract. 2014;105:295-301.

Mohan V, Balasubramanyam M. Fenugreek and insulin resistance. J Assoc Physicians India. 2001;49:1055-6.

Muraki E, Chiba H, Taketani K, Hoshino S, Tsuge N, Tsunoda N, et al. Fenugreek with reduced bitterness prevents dietinduced metabolic disorders in rats. Lipids Health Dis. 2012;11:58.

Nyenwe EA, Jerkins TW, Umpierrez GE, Kitabchi AE. Management of type 2 diabetes: evolving strategies for the treatment of patients with type 2 diabetes. Metabolism. 2011;60:1-23.

O'Connor N, Tredger J, Morgan L. Viscosity differences between various guar gums. Diab tologia. 1981;20:612-5.

Osborne TF. Sterol regulatory element-binding proteins (SREBPs): key regulators of nutritional homeostasis and insulin action. J Biol Chem. 2000;275:32379-82.

Pagliassotti MJ, Knobel SM, Shahrokhi KA, Manzo A, Hill J. Time course of adaptation to a high-fat diet in obesity-resistant and obesity-prone rats. The American journal of physiology. 1994;267:R659-R64.

Pessin JE, Saltiel AR. Signaling pathways in insulin action: molecular targets of insulin resistance. J Clin Invest. 2000;106:165-9.

Previs SF, Withers DJ, Ren J-M, White MF, Shulman GI. Contrasting effects of IRS-1 versus IRS-2 gene disruption on carbohydrate and lipid metabolism in vivo. J Biol Chem. 2000; 275: 38990-4.

Respondek F, Myers K, Smith TL, Wagner A, Geor RJ. Dietary supplementation with short-chain fructo-oligosaccharides improves insulin sensitivity in obese horses. J Anim Sci. 2011; 89:7783.

Roberts KT. The Potential of Fenugreek (Trigonella foenum-graecum) as a Functional Food and Nutraceutical and Its Effects on Glycemia and Lipidemia. J Med Food. 2011;14:1485-9.

Sharma R. Effect of fenugreek seeds and leaves on blood glucose and serum insulin responses in human subjects. Nutrition Research. 1986;6:1353-64. 
Sharma R, Raghuram T, Rao NS. Effect of fenugreek seeds on blood glucose and serum lipids in type I diabetes. Eur J Clin Nutr. 1990;44:301-6.

Shepherd PR, Gnudi L, Tozzo E, Yang H, Leach F, Kahn BB. Adipose cell hyperplasia and enhanced glucose disposal in transgenic mice overexpressing GLUT4 selectively in adipose tissue. J Biol Chem. 1993;268:22243-6.

Shimomura I, Matsuda M, Hammer RE, Bashmakov Y, Brown MS, Goldstein JL. Decreased IRS-2 and Increased SREBP-1c Lead to Mixed Insulin Resistance and Sensitivity in Livers of Lipodystrophic and ob/ob Mice. Mol Cell. 2000;6:77-86.

Sivitz WI, DeSautel SL, Kayano T, Bell GI, Pessin JE. Regulation of glucose transporter messenger RNA in insulin-deficient states. Nature. 1989;340:72-4.

Smith DL, Jr., Nagy TR, Wilson LS, Dong S, Barnes S, Allison DB. The effect of mannan oligosaccharide supplementation on body weight gain and fat accrual in $\mathrm{C} 57 \mathrm{Bl} / 6 \mathrm{~J}$ mice. Obesity (Silver Spring). 2010;18:995-9.

Stades AM, Heikens JT, Erkelens DW, Holleman F, Hoekstra JB. Metformin and lactic acidosis: cause or coincidence? A review of case reports. J Intern Med. 2004;255:179-87.

Surwit RS, Kuhn CM, Cochrane C, McCubbin JA, Feinglos MN. Diet-induced type II diabetes in C57BL/6J mice. Diabetes. 1988;37:1163-7.

Takahashi A, Motomura K, Kato T, Yoshikawa T, Nakagawa Y, Yahagi N, et al. Transgenic mice overexpressing nuclear SREBP-1c in pancreatic $\beta$-cells. Diabetes. 2005;54:492-9.

Turner R, Holman R, Cull C, Stratton I, Matthews D, Frighi $\mathrm{V}$, et al. Intensive blood-glucose control with sulphonylureas or insulin compared with conventional treatment and risk of complications in patients with type 2 diabetes (UKPDS 33). Lancet. 1998;352:837-53

Valverde AM, Burks DJ, Fabregat I, Fisher TL, Carretero J, White MF, et al. Molecular mechanisms of insulin resistance in IRS-2deficient hepatocytes. Diabetes. 2003; 52:2239-48.

Valverde AM, Fabregat I, Burks DJ, White MF, Benito M. IRS-2 mediates the antiapoptotic effect of insulin in neonatal hepatocytes. Hepatology. 2004;40:1285-94.

Veerapur V, Prabhakar K, Thippeswamy B, Bansal P, Srinivasan K, Unnikrishnan M. Antidiabetic effect of $<$ i $>$ Ficus racemosa $</ \mathrm{i}>$ Linn. stem bark in high-fat diet and low-dose streptozotocin-induced type 2 diabetic rats: A mechanistic study. Food Chem. 2012;132:186-93.
Vijayakumar MV, Pandey V, Mishra GC, Bhat MK. Hypolipidemic effect of fenugreek seeds is mediated through inhibition of fat accumulation and upregulation of LDL receptor. Obesity (Silver Spring). 2010;18:667-74.

Vijayakumar MV, Singh S, Chhipa RR, Bhat MK. The hypoglycaemic activity of fenugreek seed extract is mediated through the stimulation of an insulin signalling pathway. British Journal of Pharmacology. 2005;146:41-8.

Wang D, Han J, Yu Y, Li X, Wang Y, Tian H, et al. Chitosan oligosaccharide decreases very-low-density lipoprotein triglyceride and increases high-density lipoprotein cholesterol in highfat-diet-fed rats. Exp Biol Med (Maywood). 2011;236:1064-9.

Watson RR, Preedy VR. Bioactive foods in promoting health : fruits and vegetables. Amsterdam: Academic; 2010.

Watson RT, Kanzaki M, Pessin JE. Regulated membrane trafficking of the insulin-responsive glucose transporter 4 in adipocytes. Endocr Rev. 2004;25:177-204.

Yang JY, Moon E, Nam SH, Friedman M. Antidiabetic effects of rice hull smoke extract on glucose-regulating mechanism in type 2 diabetic mice. J Agric Food Chem. 2012;60:7442-9.

Zhang L, Yang J, Chen X-q, Zan K, Wen X-d, Chen H, et al. Antidiabetic and antioxidant effects of extracts from $<\mathrm{i}>$ Potentilla discolor $</ \mathrm{i}>$ Bunge on diabetic rats induced by high fat diet and streptozotocin. J Ethnopharmacol. 2010;132:518-24.

Zhang R, Zhou J, Jia Z, Zhang Y, Gu G. Hypoglycemic effect of Rehmannia glutinosa oligosaccharide in hyperglycemic and alloxan-induced diabetic rats and its mechanism. J Ethnopharmacol. 2004;90:39-43

Zhu C-F, Peng H-B, Liu G-Q, Zhang F, Li Y. Beneficial effects of oligopeptides from marine salmon skin in a rat model of type 2 diabetes. Nutrition. 2010;26:1014-20.

\section{How to cite this article:}

Amit D Kandhare, Subhash L Bodhankar, Vishwaraman Mohan, Prasad A Thakurdesai. Prophylactic efficacy and possible mechanisms of oligosaccharides based standardized fenugreek seed extract on high-fat diet-induced insulin resistance in C57BL/6 mice. J App Pharm Sci, 2015; 5 (03): 035-045. 